\title{
Variation in $\mathrm{x}$-box binding protein 1 (XBP1) expression and its dependent endoplasmic reticulum chaperones does not regulate adiponectin secretion in dairy cows
}

\author{
C. S. Krumm, S. L. Giesy, C. L. Orndorff, and Y. R. Boisclair ${ }^{1}$ \\ Department of Animal Science, Cornell University, Ithaca, NY 14853
}

\begin{abstract}
Adiponectin is an insulin-sensitizing hormone produced predominantly by adipose tissue; it circulates as oligomers of $3,6,18$, or more units. Plasma adiponectin might be involved in the development of insulin resistance in transition dairy cows because it falls to a nadir around parturition. The possibility that this regulation occurs through a post-transcriptional mechanism was suggested in a previous study that showed unchanged adiponectin mRNA abundance combined with reduced expression of endoplasmic reticulum (ER) chaperones implicated in assembly of adiponectin oligomers. Expression of ER chaperones is controlled by $\mathrm{x}$-box binding protein 1 (XBP1) and activating transcription factor 6 (ATF6), suggesting a model whereby transcriptional regulation of ER chaperones during the transition period contributes to the regulation of adiponectin production. In support of this model, XBP1 expression in adipose tissue, measured either as the active spliced $X B P 1 \mathrm{mRNA}$ or as the total of all $X B P 1 \mathrm{mRNA}$ isoforms, was $45 \%$ lower on $\mathrm{d} 8$ of lactation than $4 \mathrm{wk}$ before parturition; ATF6 mRNA abundance remained unchanged over the same period. To assess the functional importance of $X B P 1$, preadipocytes isolated from pregnant cows were differentiated into adipocytes that secrete adiponectin. Infection of differentiating cells with an adenovirus expressing the active spliced version of bovine $X B P 1$ did not alter adiponectin mRNA but increased the expression of ER chaperones 1.5- to 5 -fold. Despite the latter, XBP1 overexpression did not affect the total amount of adiponectin secreted in medium. In additional experiments, adiponectin production was dependent on exogenous lipid in the medium and was reduced during incubation with tumor necrosis factor- $\alpha(\mathrm{TNF} \alpha)$. Accordingly, we asked whether the repressive effects of these factors on adiponectin pro-
\end{abstract}

Received October 25, 2017.

Accepted January 26, 2018.

${ }^{1}$ Corresponding author: yrb1@cornell.edu duction were related to a reduction in the expression of adiponectin or determinants of ER function (XBP1, $A T F 6$, and ER chaperones). Exogenous lipid had no effect on the expression of any of these genes, whereas TNF $\alpha$ repressed adiponectin mRNA abundance by $61 \%$ but had little effect on determinants of ER function. Overall, this work shows that XBP1 is a positive regulator of ER chaperone expression in adipose tissue but provides no support for XBP1 and its dependent ER chaperones in the regulation of adiponectin production in bovine adipocytes. Mechanisms accounting for reduced plasma adiponectin in transition cows remain poorly understood.

Key words: adipocyte, transition dairy cow, tumor necrosis factor $\alpha$, growth hormone

\section{INTRODUCTION}

Dairy cows in early lactation (EL) suffer from significant deficits in virtually all major classes of organic nutrients, including the lactose precursor glucose (Bell, 1995). Dairy cows cope with this nutritional insufficiency by calling on adaptations such as insulin resistance (IR). Insulin resistance is beneficial in EL because it favors partitioning of glucose to the mammary gland where uptake is independent of insulin (Bell and Bauman, 1997). The IR of EL is likely driven in part by increased plasma growth hormone $(\mathbf{G H})$, given its ability to suppress insulin-stimulated glucose uptake in adipose tissue and skeletal muscle (Bauman and Vernon, 1993; Bell and Bauman, 1997; Block et al., 2001). Increased plasma fatty acids may also be involved through induction of signals interfering with insulin signaling such as ceramide and the cytokine tumor necrosis factor- $\alpha$ (TNFo; Pires et al., 2007; Sadri et al., 2010; Rico et al., 2015). One hormone that has not been extensively studied in the context of the IR of EL is adiponectin. We and others have shown that the plasma concentration of adiponectin drops in parallel with the rise of IR during the transition from late pregnancy $(\mathbf{L P})$ to EL in dairy cows (Giesy et al., 2012; Mielenz et al., 2013; 
Singh et al., 2014a). This observation may be relevant to the IR of EL because work in other species has implicated adiponectin as an insulin-sensitizing hormone (Maeda et al., 2002; Nawrocki et al., 2006; Kim et al., 2007).

Adiponectin is a $30-\mathrm{kDa}$ protein secreted predominantly by adipose tissue (Kadowaki and Yamauchi, 2005; Dadson et al., 2011; Wang and Scherer, 2016). Unlike most other adipokines, adiponectin circulates as low-, medium-, and high-molecular-weight complexes containing 3,6 , or 18 or more adiponectin monomers (Kadowaki et al., 2008; Wang et al., 2008). Adiponectin oligomer assembly occurs within the endoplasmic reticulum (ER) and is facilitated by interactions with ER chaperones. Endoplasmic reticulum chaperones implicated in adiponectin folding and assembly into oligomers include glucose-regulated protein $78 \mathrm{kDa}$ (GRP78), ER protein 44 (ERP44), ER oxidoreductase $1 \alpha(\mathbf{E R O} 1 \alpha)$, protein disulfide isomerase family A, member 6 (PDIA6), disulfide bond oxidoreductase A-like protein (DSBA-L), and Golgi associated, gamma adaptin ear containing, ARF binding protein 1 (GGA1) (Wang and Scherer, 2008; Liu and Liu, 2009). Interestingly, the reduction in plasma adiponectin seen in transition dairy cows was not associated with reduced adiponectin mRNA in white adipose tissue (WAT) but rather with lower expression of the ER chaperones GRP78, ERP44, and PDIA6 (Giesy et al., 2012). Others have also observed a lack of correspondence between changes in plasma adiponectin and adiponectin mRNA abundance in adipose tissue of transition dairy cows (Lemor et al., 2009; Saremi et al., 2014; Singh et al., 2014b). These data suggest that variation in ER chaperone expression may be an important determinant of adiponectin production in transition dairy cows.

Endoplasmic reticulum chaperone expression is regulated in part through 2 master transcription factors known as x-box binding protein 1 (XBP1) and activating transcription factor 6 (ATF6; also known as ATF6 ; Lee et al., 2003; Shoulders et al., 2013). Notably, plasma adiponectin is increased by approximately $50 \%$ in mice overexpressing the active spliced form of XBP1 (XBP1s) specifically in adipose tissue (Sha et al., 2014). Accordingly, we hypothesized that reduced ER chaperone expression in transition dairy cows would be associated with lower expression of these transcription factors. We found this association to be true only for XBP1, leading us to ask whether its overexpression in adipocytes would increase ER chaperone expression and adiponectin secretion. Finally, we asked whether ER chaperone expression is downregulated when bovine adipocytes are exposed to conditions leading to reduced adiponectin secretion.

\section{MATERIALS AND METHODS}

\section{Source of Adipose Tissue}

All experiments were performed on multiparous Holstein cows and were approved by the Cornell Institutional Animal Care and Use Committee. Gene expression of XBP1 and ATF 6 was measured in WAT collected in a previous study reporting on the regulation of ER chaperones during the transition period (Giesy et al., 2012). In brief, WAT was obtained from the subcutaneous tail-head depot of 10 cows in LP (d $-29 \pm 2$, relative to parturition on $\mathrm{d} 0$ ) and again in EL (d 8). White adipose tissue samples were frozen at $-80^{\circ} \mathrm{C}$ until used for total RNA isolation.

White adipose tissue used for isolation of bovine preadipocytes was obtained from the subcutaneous tail-head depot of Holstein cows at the start of the dry-off period, approximately $7 \mathrm{wk}$ before expected parturition. All cows were of parity $\geq 1$ and were in good body condition (BCS $\geq 3.0$ ). Immediately after biopsy, WAT was immersed in growth medium [Dulbecco's modified Eagle medium (DMEM)/F12 (Thermo Fisher, Waltham, MA) supplemented with $10 \%$ supplemented bovine growth serum (Fetalgro, Rocky Mountain Biologicals Inc., Missoula, MT), penicillinstreptomycin (50 U/mL, Thermo Fisher), glutamine (2 $\mathrm{m} M$; GlutaMAX, Thermo Fisher), and amphotericin B $(1 \mu \mathrm{g} / \mathrm{mL}$; Thermo Fisher $)]$ and transported to the laboratory.

\section{Isolation, Differentiation, and Study of Bovine Preadipocytes}

Bovine preadipocytes were isolated and differentiated into adipocytes as previously described (Lengi and Corl, 2010). In brief, WAT was rinsed in a solution of $20 \%$ betadine and growth medium, followed by a single wash with fresh growth medium. Pieces of WAT $\left(\sim 1 \mathrm{~mm}^{3}\right)$ were placed onto $100-\mathrm{mm}$ dishes and kept in place with a coverslip attached to the growth surface of the cell dish with vacuum grease. After $10 \mathrm{~d}$, fibroblastlike cells growing out of the explants were recovered by trypsinization and seeded into 100-mm dishes. Cells were reseeded when $90 \%$ confluent into $60-\mathrm{mm}$ dishes coated with gelatin (Sigma Aldrich, St. Louis, MO). Cells were incubated over the first $48 \mathrm{~h}$ with adipocyte differentiation medium [DMEM/F12 $+10 \mu \mathrm{g} / \mathrm{mL}$ insulin; Sigma Aldrich), rosiglitazone (1 $\mu M$; Sigma Aldrich), intralipid (2\% vol/vol of Intralipid 20\%; Sigma Aldrich), penicillin-streptomycin (50 U/mL; Thermo Fisher), glutamine ( $2 \mathrm{~m} M$; Thermo Fisher), and amphotericin B (1 $\mu \mathrm{g} / \mathrm{mL}$; Thermo Fisher $)$ s supplemented 
with dexamethasone $(0.25 \mu M$; Sigma Aldrich) and 3-isobutyl-1-methylxanthine (0.5 m $M$; Sigma Aldrich), and adipocyte differentiation medium alone thereafter. White adipose tissue explants and cells were kept at $37^{\circ} \mathrm{C}$ and $5 \% \mathrm{CO}_{2}$ with medium changed every $2 \mathrm{~d}$.

For experiments involving adenoviruses, adipocytes were infected at $1700 \mathrm{~h}$ on d 6 of differentiation followed by a medium change $15 \mathrm{~h}$ later. Total RNA was collected on d 9 of differentiation. Medium was collected on d 9 or 10 of differentiation following a $24-\mathrm{h}$ period of conditioning. In other studies, adipocytes were incubated between d 6 and 8 with either PBS (control), $100 \mathrm{ng} / \mathrm{mL}$ bovine GH (Protiva, St. Louis, MO), or 10 $\mathrm{ng} / \mathrm{mL}$ of human TNFa (R\&D Systems, Minneapolis, MN). Medium and total RNA were collected on d 8 of differentiation.

Oil-red O staining was used to confirm lipid accumulation in differentiating cells. In brief, cells were washed with PBS and fixed with $10 \%$ formalin for $1 \mathrm{~h}$ at room temperature. Following 2 washes with $60 \%$ isopropanol, cells were stained with Oil-red O (Sigma Aldrich) for 10 min at room temperature and analyzed by Axiovert 40 Microscope bright light microscopy (Carl Zeiss Microscopy, Thornwood, NY) at $10 \times$ magnification.

\section{Construction of an Adenovirus Expressing Bovine XBP1s}

Unconventional splicing of mature XBP1 mRNA by inositol-requiring enzyme-1 (IRE1) gives rise to the active spliced XBP1s (Glimcher, 2010). To increase the relative abundance of $X B P 1 s$ mRNA, bovine MAC-T cells were incubated with $2 \mathrm{~m} M$ dithiothreitol for 4 $\mathrm{h}$ as described by Wang et al. (2011). Then, cDNAs were generated by reverse transcription of total RNA followed by high-fidelity amplification of the XBP1s cDNA using previously described procedures (Boisclair et al., 1996). The XBP1s cDNA was subcloned into the adenoviral shuttle vector pAd-CMV and shown by sequencing to correspond exactly to bovine XBP1s (Ref Seq NM_001034727.3). The bovine XBP1s adenovirus was generated using the AdEasy system as previously described (Luo et al., 2007). In brief, the plasmid was linearized using the restriction enzyme PmeI and transformed into AdEasier bacteria containing the adenoviral backbone plasmid pAdEasy-1. As a result, the bovine $X B P 1 s$ cDNA was recombined into the pAdEasy-1, giving pAdEasy-XBP1s. Adenovirus particles were generated by transfecting human embryonic kidney 293a cells with Pac-I-linearized pAdEasy-XBP1s using Lipofectamine 2000 (Thermo Fisher). The virus was then amplified via 5 rounds of human embryonic kidney 293a infection. Adenoviruses expressing mCherry under the control of the CMV (cytomegalovirus) promoter (Cherry; Vector Biolabs, Malvern, PA) were amplified in parallel using the exact same procedure.

\section{Western Blot Analysis}

Medium from 4 individual $60-\mathrm{mm}$ dishes was pooled and concentrated to $100 \mu \mathrm{L}$ using centrifugal units with a molecular weight cutoff of $10 \mathrm{kDa}$ (Amicon Ultra-4; Merck, Kenilworth, NJ). Total cellular extracts were prepared from bovine adipocytes by lysis with radioimmunoprecipitation assay (RIPA) buffer $[10 \mathrm{~m} M$ Tris$\mathrm{HCl}$ (pH 7.4), $150 \mathrm{~m} M \mathrm{NaCl}, 1 \%$ Nonidet P-40, $1 \mathrm{mM}$ phenylmethylsulfonyl fluoride, $1 \mathrm{~m} M$ EDTA, $1 \mathrm{~m} M$ $\mathrm{NaF}, 0.25 \%$ sodium deoxycholate, and $10 \%$ glycerol, supplemented with protease and phosphatase inhibitors (Halt phosphatase inhibitor mixture EDTA-free; Thermo Fisher)]. Protein concentrations of cellular extracts were determined using the bicinchoninic acid assay (Thermo Fisher). Concentrated medium $(18 \mu \mathrm{L})$ or fixed amounts of cellular extract $(20-40 \mu \mathrm{g})$ were mixed with Laemmli buffer containing dithiothreitol and mercaptoethanol and boiled for $10 \mathrm{~min}$ (Giesy et al., 2012). Proteins were separated on $13 \%$ polyacrylamide gels and transferred onto nitrocellulose membranes (Protran, Schleicher, and Schuell Bioscience, Dassel, Germany). Membranes were blocked in Tris-buffered saline with Tween-20 (0.05 $M$ Tris-HCl, pH 7.4, $0.2 \mathrm{M} \mathrm{NaCl}$, and $0.1 \%$ Tween-20) containing $5 \%$ (wt/vol) nonfat dried skim milk. Membranes were then immunodecorated with a mouse primary antibody against human adiponectin (a gift from Dr. Tohru Funahashi, Osaka University; Suita, Japan) and a rabbit primary antibody against human $\beta$-actin (Cell Signaling, Danvers, MA). In preliminary immunoblotting experiments with bovine adipose tissue and plasma, the human adiponectin antibody yielded a single signal at the expected size for bovine adiponectin $(30 \mathrm{kDa})$; this signal was eliminated when immunoblotting was performed in the presence of purified bovine adiponectin. The human adiponectin antibody was adopted because it has greater affinity for bovine adiponectin than the antibodies used in our previous work (Giesy et al., 2012). As reported by the commercial supplier and in previously published work (Zhou et al., 2008), the human $\beta$-actin antibody detected a signal at the expected size for bovine $\beta$-actin $(45 \mathrm{kDa})$. Primary antibodies were diluted at 1:1,000 ( $\beta$-actin) or $1: 20,000$ (adiponectin) in blocking solution. Signals were developed with 1:20,000 dilution of either IR Dye 800 goat anti-rabbit or goat anti-mouse secondary antibody (LI-COR Biotechnology, Lincoln, NE) and visualized with the LI-COR Odyssey infrared imaging system. 


\section{RNA Extraction and Analysis of Gene Expression}

White adipose tissue biopsies and bovine adipocytes were lysed with Qiazol (Qiagen, Valencia, CA) followed by total RNA purification using RNeasy Mini columns and on-column RNase-free DNase treatment (Qiagen). Reverse transcription reactions were performed with 1 $\mu \mathrm{g}$ of mRNA in a total volume of $20 \mu \mathrm{L}$ with the highcapacity cDNA reverse transcription kit and RNase inhibitor (Applied Biosystems, Foster City, CA). Gene expression was analyzed with quantitative real-time PCR assays using Power SYBR Green Mix (Applied Biosystems). Real-time PCR assays were performed in duplicate with a total reaction volume of $25 \mu \mathrm{L}$ containing $500 \mathrm{n} M$ concentrations of each primer and reverse transcribed mRNA (25 ng except for the internal standard gene 18S, $2.5 \mathrm{ng}$ ). The sequences of all primers used are given in Supplementary Table S1 (https:// doi.org/10.3168/jds.2017-14048). All mRNA data were analyzed using a relative standard curve based on serial dilution of pooled cDNA from bovine adipocytes. Unknown sample expression levels were calculated from the standard curve and adjusted to the geometric mean expression of $\beta$-actin and $18 \mathrm{~S}$.

\section{Statistical Analysis}

Data were analyzed by a mixed model using the fit model procedure of JMP Pro 11.0 statistical software (SAS Institute Inc., Cary, NC). For XBP1s mRNA abundance during the transition period, the model accounted for physiological stage (LP vs. EL) as the fixed effect and animal as the random effect. For the time course of differentiation, the model accounted for time $(0,4,6,8$, and $10 \mathrm{~d})$ as the fixed effect and cell dish as the random effect. If significant, the effect of time was partitioned into linear, quadratic, and cubic contrasts. For the effect of $X B P 1 s$ overexpression, the model accounted for adenovirus (Cherry vs. XBP1s) as the fixed effect and cell dish as the random effect. For the intralipid experiment, the model accounted for treatment ( - vs. + intralipid) as the fixed effect and cell dish as the random effect. For the GH and TNF $\alpha$ experiments, the model accounted for treatment (control vs. GH or $\mathrm{TNF} \alpha$ ) as the fixed effect and cell dish as the random effect. The level of statistical significance was set at $P$ $<0.05$.

\section{RESULTS}

\section{Reduced XBP1 Expression in Adipose Tissue of Transition Dairy Cows}

In previous work, we showed that plasma adiponectin decreased by $40 \%$ between LP and EL (Giesy et al.,
2012). This reduction was associated with reduced WAT expression of the ER chaperones GRP78, ERP44, and $P D I A 6$, which are under transcriptional regulation by XBP1 and ATF6 (Shoulders et al., 2013). Accordingly, we asked whether the expression of these transcription factors is regulated in the WAT of these transition dairy cows. White adipose tissue $X B P 1$ expression measured either as the active spliced $X B P 1 s$ mRNA or as the total of all $X B P 1 \mathrm{mRNA}$ isoforms was reduced by approximately $45 \%$ between LP and EL (Figure $1 \mathrm{~A}, P<0.001$ ), whereas expression of ATF6 remained unchanged (Figure 1B). Expression of the ATF6 paralogue $A T F 6 B$ was also not regulated between LP and EL (Figure 1B). These data raise the possibility that XBP1-dependent expression of ER chaperones contributes to reduced plasma adiponectin in EL.

\section{Capacity of Primary Bovine Adipocytes to Secrete Adiponectin}

As a first step to evaluate the possibility of a causal relation between XBP1 expression and adiponectin production, we asked whether preadipocytes isolated from adipose tissue could differentiate into adiponectinsecreting adipocytes. Bovine preadipocytes were grown out of WAT explants and upon confluence, incubated in differentiation medium over $10 \mathrm{~d}$. Lipid accumulation was not detected by Oil-red $\mathrm{O}$ on d 0 but became obvious by d 6 of differentiation and peaked in abundance and intensity by d 8 (Supplementary Figure S1A; https://doi.org/10.3168/jds.2017-14048). Acquisition of the adipogenic phenotype was confirmed by maximal expression of the adipogenic marker fatty acid binding protein-4 $(\boldsymbol{F A B P} 4)$ within $4 \mathrm{~d}$ of incubation in differentiation medium (Figure $2 \mathrm{~A}, P<0.01$ ). Leptin and adiponectin mRNA were undetectable on differentiation $\mathrm{d} 0$ but increased in a linear fashion over the next $10 \mathrm{~d}$ (Figure 2A, $P<0.05$ or less). Finally, we assessed the presence of adiponectin in cells and medium collected during differentiation (Figure 2B). Adiponectin was undetectable at all times in cellular extracts and in medium collected between d 0 and 4 of differentiation. Adiponectin was first detected in medium collected between $\mathrm{d} 4$ and 6 of differentiation and increased in abundance over the next 2 collection periods (Figure 2B). Together, these findings demonstrate that bovine preadipocytes differentiated into adipocytes that produce and secrete adiponectin.

\section{Effect of XBP1 Overexpression on ER Chaperone Expression and Adiponectin Secretion}

First, we asked whether adenoviruses could efficiently infect cells undergoing adipogenic differentiation. Bo- 
A

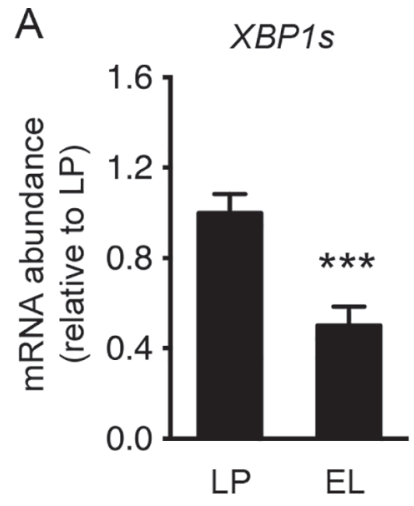

B

ATF6

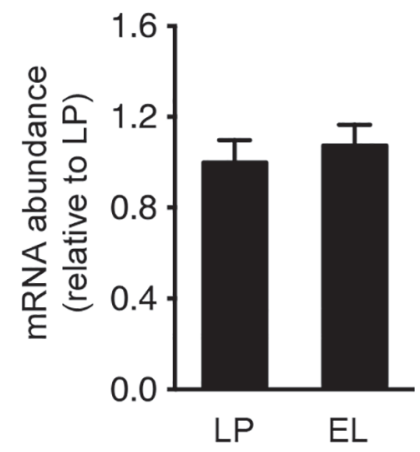

Total XBP1

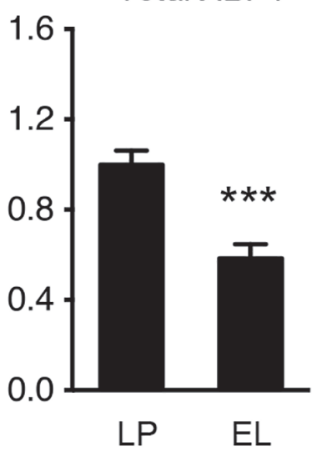

in medium between d 8 and 9 of differentiation (i.e., between 48 and $72 \mathrm{~h}$ following infection; Figure 3C). Similarly, extending the infection for another $24 \mathrm{~h}$ did not affect adiponectin secretion in medium collected between d 9 and 10 of differentiation (Figure 3C). Overall, these data show that $X B P 1 s$ is a positive regulator of GRP 78, ERP44, and PDIA6 expression but do not support a role for $X B P 1 s$ in regulating adiponectin production in bovine adipocytes.

\section{Variation in Adipocyte Adiponectin Secretion Despite Invariant ER Chaperone Expression}

Next, we investigated whether treatments curtailing adiponectin production by bovine adipocytes caused a parallel reduction in ER chaperone expression. We first asked whether exogenous lipids, mimicked by supplementation with intralipid, affected adiponectin secretion. Preadipocytes were cultured for $8 \mathrm{~d}$ in differentiation medium supplemented with or without intralipid. Absence of intralipid abrogated adiponectin secretion in medium (Figure 4A), even though adiponectin mRNA and expression of the adipogenic differentiation marker $F A B P 4$ were unaffected (Figure 4B). Similarly, absence of intralipid had no effect on the mRNA abundance of the master transcription factors of ER function (XBP1s and $A T F 6$ ) and their dependent ER chaperones previously implicated in adiponectin secretion [GRP 78 , ERP44, ERO1A, PDIA6, GSTK1 (referred to throughout the manuscript as $D S B A-L)$, and GGA1; Figures $4 \mathrm{C}$ and $4 \mathrm{D}]$. These data show that intralipid is required for adiponectin production by differentiated bovine adipocytes via an ER chaperone-independent mechanism.

Finally, we assessed the effects of $\mathrm{GH}$ and $\mathrm{TNF} \alpha$ on adiponectin secretion, as both have been shown to reduce adiponectin secretion in human or murine cell culture systems (Nilsson et al., 2005; Lim et al., 2008). Bovine adipocytes were treated with $\mathrm{GH}$ or TNF $\alpha$ between d 6 and 8 of differentiation. Treatment with GH had no effect on $F A B P 4$ expression, adiponectin mRNA level, or adiponectin secretion in medium (Figures 5A and 5B). On the other hand, treatment with $\mathrm{TNF} \alpha$ caused a $27 \%$ reduction in the $\mathrm{mRNA}$ abundance of the adipocyte differentiation marker $F_{A B P}$ (Figure $6 \mathrm{~A}, P$ $<0.05)$. Treatment with $\mathrm{TNF} \alpha$ decreased adiponectin mRNA abundance by $86 \%$ (Figure $6 \mathrm{~A}, P<0.05$ ) and adiponectin in medium by $29 \%$ (Figure $6 \mathrm{~B}, P<$ 0.01). Treatment with TNF $\alpha$ also reduced expression of GRPr8 by $44 \%(P<0.05)$ but had no effect on the expression of other ER chaperones (Figure 6C). These data suggest that the effects of $\mathrm{TNF} \alpha$ on adiponectin secretion are mediated through reduced adiponectin mRNA and possibly repression of GRPr8 expression. sion did not affect the amount of adiponectin secreted 


\section{DISCUSSION}

The plasma concentration of adiponectin in transition dairy cows decreases by $40 \%$ during the last 2 to $3 \mathrm{wk}$ before parturition and is followed by a gradual increase during lactation (Giesy et al., 2012; Mielenz et al., 2013; Singh et al., 2014a). In late pregnancy and early lactation, however, changes in plasma adiponectin occur in the absence of corresponding changes in adiponectin mRNA expression in subcutaneous WAT (Lemor et al., 2009; Giesy et al., 2012). This is best illustrated by a recent study in which changes in plasma adiponectin and indices of adiponectin production in WAT depots were studied between parturition and d 105 of lactation (Saremi et al., 2014; Singh et al., 2014b). That work showed that adiponectin recovered fully in both plasma and individual depots by $\mathrm{d} 42$ of lactation in complete absence of any changes in mRNA. A lack of relation between changes in adiponectin mRNA and plasma adiponectin is not unique to transition dairy cows. For example, human subjects undergoing extensive weight loss experience increased plasma adiponectin in the absence of changes in adiponectin mRNA (Behre et al., 2007). Longitudinal studies following rhesus monkeys through the development of obesity and type 2 diabetes showed a decrease in plasma adiponectin, independent of changes in adiponectin mRNA (Hotta et al., 2001). Therefore, mechanisms other than changes in WAT adiponectin mRNA are involved in reducing plasma adiponectin concentrations in many conditions, including the transition dairy cow. In this context, there is evidence for a role of ER chaperones in assembling adiponectin into oligomeric complexes (Wang et al., 2007; Liu et al., 2008; Wang and Scherer, 2008). For example, ERP44 promotes adiponectin folding through thiol-mediated retention, whereas ERO1 $\alpha$ displace adiponectin from ERP44, allowing formation of medium- and highmolecular-weight adiponectin (Wang et al., 2007). The DSBA-L protein, endowed with disulfide bond oxidoreductase activity, was also shown to be indispensable to adiponectin oligomer formation and secretion (Liu et al., 2008, 2012). Consistent with a reduced capacity of
A

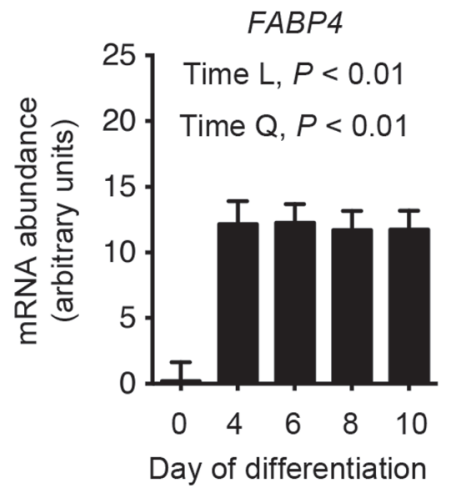

Leptin

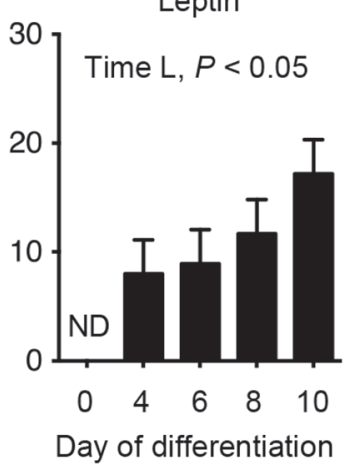

Adiponectin

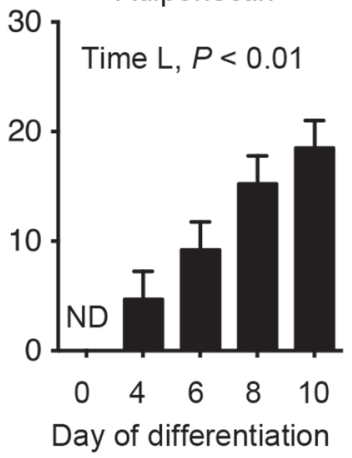

B

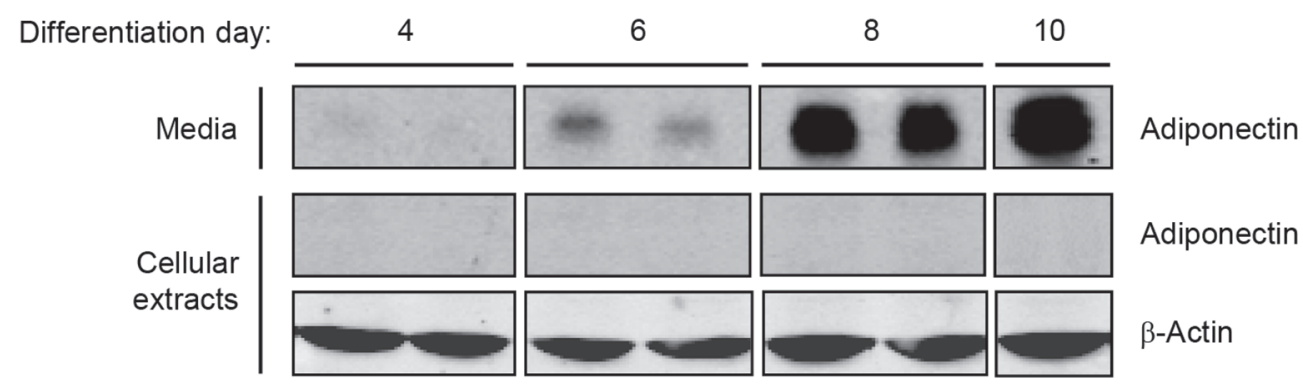

Figure 2. Capacity of primary bovine adipocytes to secrete adiponectin. Preadipocytes isolated from white adipose tissue were grown to confluence and then incubated in differentiation medium for 0 to $10 \mathrm{~d}$. (A) Total RNA was isolated over the course of differentiation and analyzed by quantitative real-time PCR for expression of fatty acid binding protein-4 (FABP4), leptin, and adiponectin. Each bar represents the mean \pm SE of mRNA abundance for the indicated gene $(\mathrm{n}=3$ per time point; $\mathrm{ND}=$ not detectable). The significance levels of the linear (L) and quadratic (Q) effects of time are given. (B) Conditioned medium and cellular extracts were collected on the indicated day of differentiation. Medium was conditioned for $2 \mathrm{~d}$ before collection. Medium and cellular extracts were analyzed for adiponectin abundance by Western immunoblotting, with $\beta$-actin as a loading control for total cellular extracts. Similar results were observed in a second experiment for variables shown in panels $\mathrm{A}$ and $\mathrm{B}$. 
A

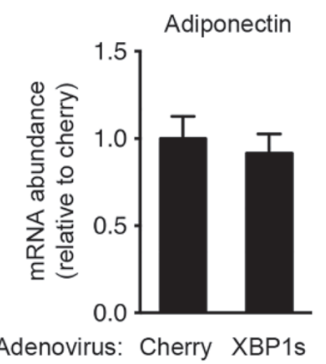

B
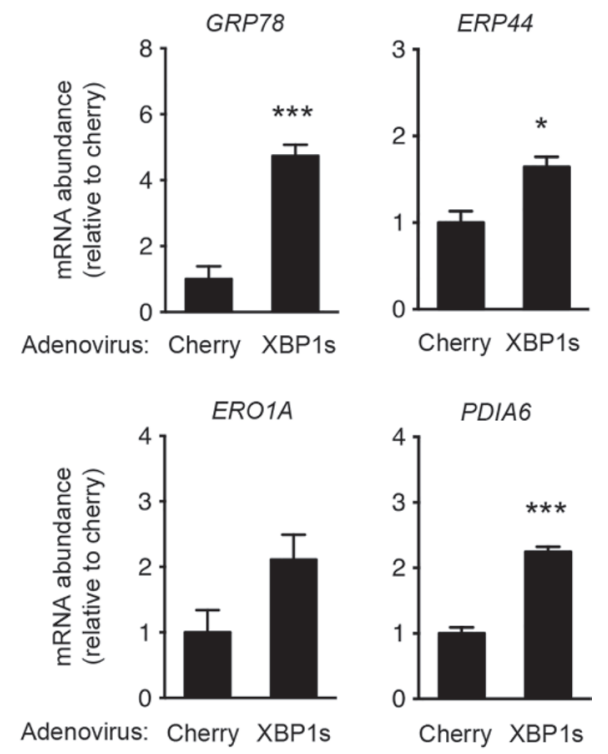

C

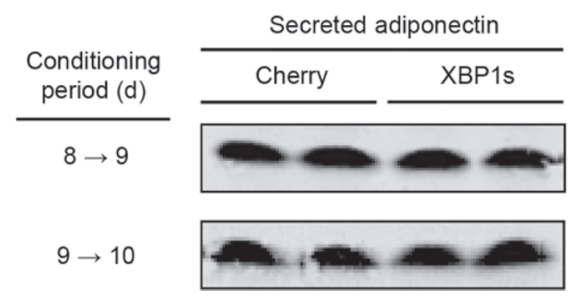

Figure 3. Effect of the spliced variant XBP1s on endoplasmic reticulum (ER) chaperone expression and adiponectin secretion in bovine adipocytes. Preadipocytes isolated from white adipose tissue were grown to confluence and then incubated in differentiation medium. Cells were infected on d 6 of differentiation with adenoviruses encoding mCherry (Cherry) or spliced variant XBP1s. (A, B) Total RNA was isolated on d 9 of differentiation and analyzed by quantitative real-time PCR for adiponectin expression or for ER chaperones expression [glucose-regulated protein, $78 \mathrm{kDa}$ (GRP78), endoplasmic reticulum protein 44 (ERP44), endoplasmic reticulum oxidoreductase $1 \propto(E R O 1 A)$, and protein disulfide isomerase family A, member 6 $(P D I A 6)]$. Expression of each gene is relative to Cherry-infected cells. Each bar represents the mean $\pm \mathrm{SE}$ of mRNA abundance for the indicated gene $(\mathrm{n}=4) ;{ }^{*} P<0.05$ and ${ }^{* * *} P<0.001$. (C) Medium conditioned between d 8 and 9 or between d 9 and 10 of differentiation was analyzed for adiponectin abundance by Western immunoblotting ( $\mathrm{n}=2$ per adenovirus and time point). Similar results were observed in a second experiment for variables shown in panels A to C.
WAT to assemble adiponectin complexes after parturition, we previously showed that expression of the ER chaperones GRP78, ERP44, and PDIA6 was lower in EL than LP in transition dairy cows (Giesy et al., 2012). These and other chaperones are positively regulated by the master regulators of ER homeostasis, XBP1 and ATF6 (Shoulders et al., 2013). Surprisingly, adipose tissue ablation of $X B P 1$ did not result in reduced plasma adiponectin (Gregor et al., 2013), an observation that could relate to maintenance of ER chaperone expression through compensatory mechanisms such as increased $A T F 6$ expression. In contrast, $X B P 1$ overexpression in mouse adipose tissue stimulated ER chaperone expression and led to 2 specific effects on plasma adiponectin: increased relative abundance of the high-molecularweight oligomer and increased total adiponectin (Sha et al., 2014). Relevance of the first effect to the biology of adiponectin in transition dairy cows is uncertain. Both medium- and high-molecular-weight adiponectin were reported in bovine plasma obtained in early lactation (Singh et al., 2014b) and in serum collected at an unspecified physiological state (Raffelsieper et al., 2012) when analyzed by nonreducing SDS-PAGE (Singh et al., 2014b). In our previous work (Giesy et al., 2012), we analyzed bovine plasma by both nonreducing SDS-PAGE and by the gold standard method developed for sizing adiponectin complexes (gel filtration chromatography followed by denaturing SDS-PAGE of fractions; Rutkowski and Scherer, 2014). Irrespective of the method used, adiponectin appeared predominantly as a high-molecular-weight complex, with no evidence of a shift in its molecular weight distribution between late pregnancy and early lactation (Giesy et al., 2012). On the other hand, the ability of XBP1 to increase total plasma adiponectin when overexpressed appeared relevant, particularly given our finding that expression of XBP1s was reduced during the transition from LP to EL. These observations prompted us to assess the possibility that XBP1 regulates adiponectin production by modulating ER chaperones involved in adiponectin assembly.

We evaluated this possibility using preadipocytes isolated from adipose tissue and differentiated into adipocytes. Others have previously shown that this system faithfully recapitulates lipogenic regulation (Lengi and Corl, 2010), but whether it was capable of producing and secreting adiponectin was unknown. Adiponectin mRNA was undetectable on d 0 of differentiation but increased in a linear fashion over the next $10 \mathrm{~d}$. Detection of adiponectin in medium showed a similar increase over $10 \mathrm{~d}$ of differentiation. We next tested whether overexpressing XBP1s could increase adiponectin production and secretion through increased ER chaperone expression. Accordingly, adipocytes were infected with 
A Secreted adiponectin

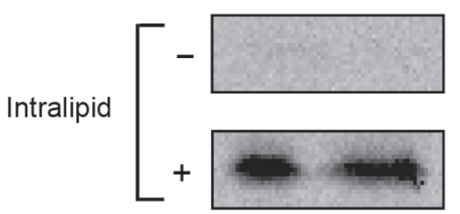

B

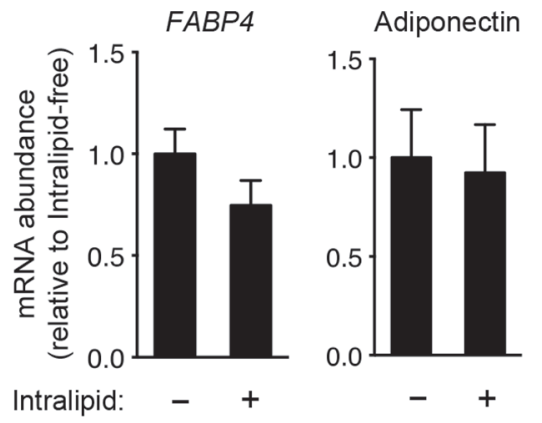

C

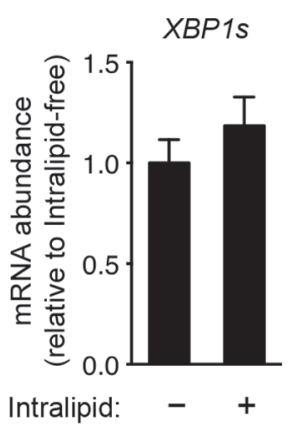

ATF6

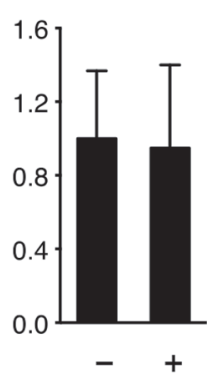

D

ER chaperones

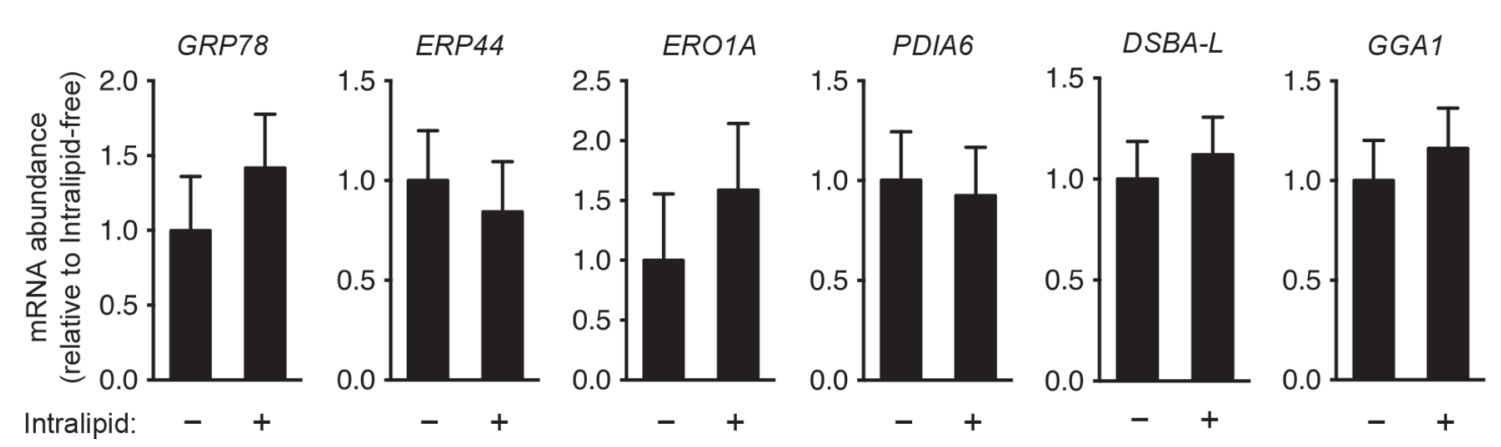

Figure 4. Effect of intralipid on endoplasmic reticulum (ER) chaperone expression and adiponectin secretion in bovine adipocytes. Preadipocytes isolated from white adipose tissue were grown to confluence and then incubated in differentiation medium in the presence $(+)$ or absence (-) of intralipid. Cells and medium were collected on d 8 of differentiation. (A) Medium conditioned between d 6 and 8 of differentiation was analyzed for adiponectin abundance by Western immunoblotting ( $\mathrm{n}=3$ per treatment). (B to D) Total RNA was analyzed by quantitative real-time PCR for expression of fatty acid binding protein-4 (FABP4), adiponectin, spliced x-box binding protein 1 (XBP1s), activating transcription factor $6(A T F 6)$, and ER chaperones [glucose-regulated protein, $78 \mathrm{kDa}(G R P 78)$, endoplasmic reticulum protein 44 ( $E R P 44$ ), endoplasmic reticulum oxidoreductase $1 \propto(E R O 1 A)$, protein disulfide isomerase family A, member 6 (PDIA6), disulfide bond oxidoreductase A-like protein $(D S B A-L)$, and Golgi associated, gamma adaptin ear containing, ARF binding protein 1 (GGA1)]. Expression is shown relative to intralipid-free treatment. Each bar represents the mean \pm SE of mRNA abundance for the indicated gene $(\mathrm{n}=3$ per treatment). Similar results were observed in a second experiment for variables shown in panels A to D.

A

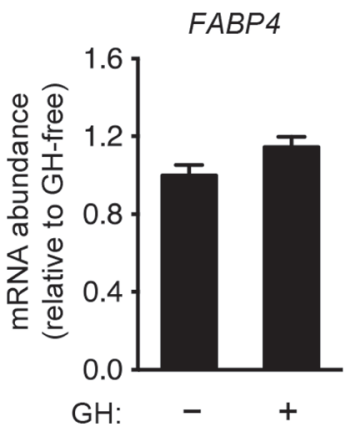

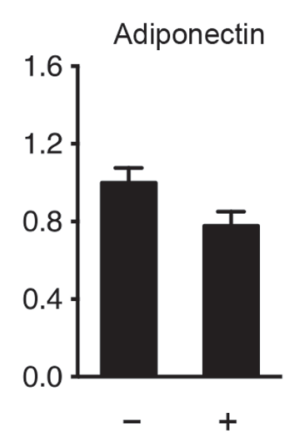

B

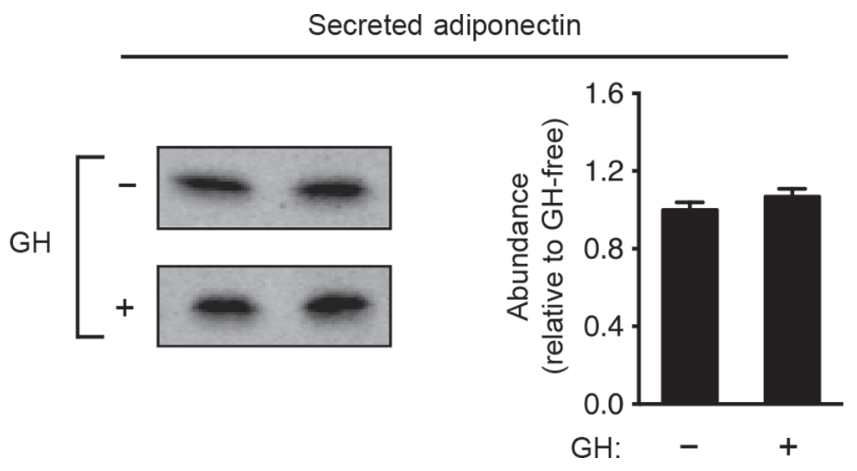

Figure 5. Effect of growth hormone $(\mathrm{GH})$ on adiponectin secretion in bovine adipocytes. Preadipocytes isolated from white adipose tissue were grown to confluence and then incubated in differentiation medium for 6 d. Cells were then incubated between d 6 and 8 with differentiation medium supplemented with (+) or without $(-) 100 \mathrm{ng} / \mathrm{mL}$ bovine GH. Cells and medium were collected on d 8 of differentiation. (A) Total RNA was analyzed by quantitative real-time PCR for expression of fatty acid binding protein-4 (FABP4) and adiponectin. Expression is given relative to GH-free treatment. Each bar represents the mean $\pm \mathrm{SE}$ of $\mathrm{mRNA}$ abundance for the indicated gene $(\mathrm{n}=4$ per treatment). (B) Left: Medium conditioned between d 6 and 8 of differentiation was analyzed for adiponectin abundance by Western immunoblotting $(\mathrm{n}=2$ per treatment). Right: The adiponectin signal was quantified and expressed relative to GH-free treatment. Each bar represents the mean \pm SE of adiponectin protein abundance $(\mathrm{n}=2$ per treatment). Similar results were observed in a second experiment for variables shown in panels $\mathrm{A}$ to $\mathrm{B}$. 
adenovirus encoding bovine XBP1s. Overexpressing $X B P 1 s$ increased the expression of ER chaperones GRP78, ERP44, and PDIA6 1.5- to 5-fold but had no effect on adiponectin mRNA or, more importantly, on the amount of adiponectin secreted in medium. It remains possible that ER chaperone expression in bovine adipocytes is already sufficient for oligomer assembly and secretion of adiponectin and that further increasing their expression has no effect. This question could be answered in future work by asking whether knockdown of $\mathrm{XBP} 1_{\mathrm{S}}, \mathrm{ATF} 6$, or both affects adiponectin secretion in this system.

Differentiation of preadipocytes requires a conserved cocktail of reagents across all species (Tchkonia et al.,
2005; Xu et al., 2005). Ruminants differ somewhat in that this cocktail is usually supplemented by exogenous lipid such as intralipid (Ortiz-Colón et al., 2009; Lengi and Corl, 2010). This prompted us to ask whether exogenous lipid affected adiponectin production and secretion. Differentiated adipocytes secreted adiponectin in medium only in the presence of intralipid even though adiponectin mRNA was unaffected. We next asked whether intralipid-mediated adiponectin secretion was associated with changes in ER chaperone expression. Intralipid had no effect on the expression of ER chaperones (GRP78, ERP44, ERO1A, PDIA6, $D S B A-L$, and $G G A 1)$ or on the expression of transcription factors regulating their expression $(X B P 1 s$ and
A

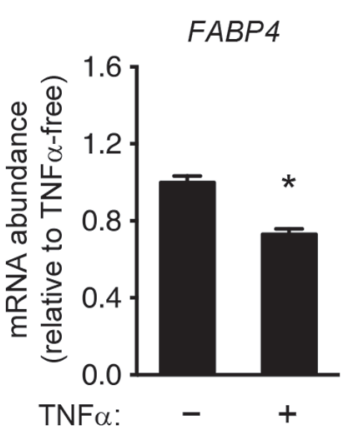

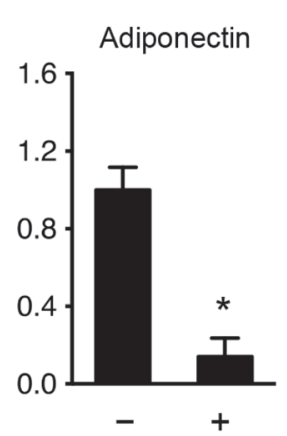

B

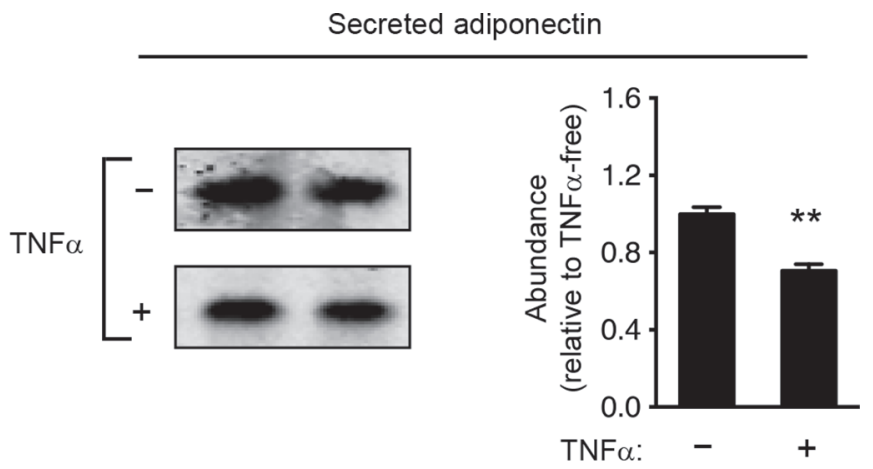

C

ER chaperones
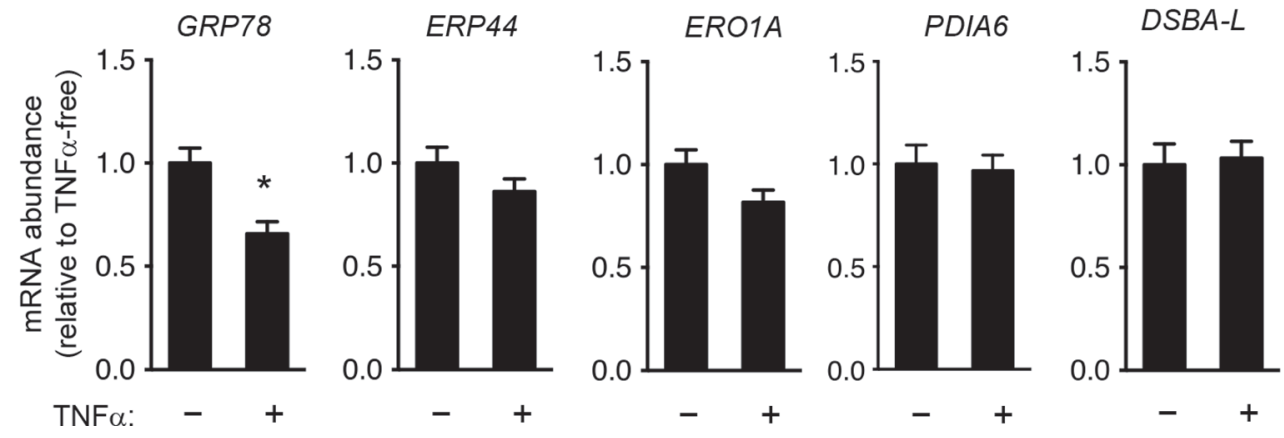

Figure 6. Effect of tumor necrosis factor $\alpha(\mathrm{TNF} \alpha)$ on endoplasmic reticulum (ER) chaperone expression and adiponectin secretion in bovine adipocytes. Preadipocytes isolated from white adipose tissue were grown to confluence and then incubated in differentiation medium for 6 d. Cells were then incubated between d 6 and 8 with differentiation medium supplemented with $(+)$ or without $(-) 10 \mathrm{ng} / \mathrm{mL}$ human $\mathrm{TNF} \alpha$. Cells and medium were collected on d 8 of differentiation. (A) Total RNA was analyzed by quantitative real-time PCR for expression of fatty acid binding protein-4 (FABP4) and adiponectin. Expression is given relative to TNF $\alpha$-free treatment. Each bar represents the mean \pm SE of mRNA abundance for the indicated gene ( $\mathrm{n}=4$ per treatment); ${ }^{*} P<0.05$. (B) Left: Medium conditioned between $\mathrm{d} 6$ and 8 of differentiation was analyzed for adiponectin abundance by Western immunoblotting ( $\mathrm{n}=2$ per treatment). Right: The adiponectin signal was quantified and expressed relative to $\mathrm{TNF} \alpha$-free treatment. Each bar represents the mean $\pm \mathrm{SE}$ of adiponectin protein abundance $(\mathrm{n}=2$ per treatment); $* * P$ $<0.01$. (C) Total RNA was analyzed by quantitative real-time PCR for mRNA abundance of ER chaperones [glucose-regulated protein, $78 \mathrm{kDa}$ $(G R P 78)$, endoplasmic reticulum protein 44 (ERP44), endoplasmic reticulum oxidoreductase $1 \alpha(E R O 1 A)$, protein disulfide isomerase family A, member 6 (PDIA6), and disulfide bond oxidoreductase A-like protein $(D S B A-L)]$. The expression of each gene is given relative to TNFo-free treatment. Each bar represents the mean $\pm \mathrm{SE}$ of mRNA abundance for the indicated gene $(\mathrm{n}=4$ per treatment $) ;{ }^{*} P<0.05$. Similar results were observed in a second experiment for variables shown in panels $\mathrm{A}$ to $\mathrm{C}$. 
ATF6). In direct agreement with our studies, treatment with fatty acids including palmitic acid, oleic acid, linoleic acid, eicosapentaenoic acid, or docosahexaenoic acid increased adiponectin secretion in the absence of changes in the expression of ER chaperones in 3T3-L1 adipocytes (DeClercq et al., 2015).

The periparturient period is characterized by rapid increases in drivers of IR, including plasma GH and adipose $\mathrm{TNF} \alpha$, suggesting a model whereby either one or both of these hormones is a negative regulator of adiponectin production and secretion (Boisclair et al., 2006; Sadri et al., 2010). We observed that TNFa suppressed adiponectin mRNA by $86 \%$ and adiponectin secretion in medium by $29 \%$ in bovine adipocytes. The ability of $\mathrm{TNF} \alpha$ to inhibit adiponectin mRNA abundance and secretion has also been demonstrated in 3T3-L1 adipocytes and mice (Fasshauer et al., 2002; Chang et al., 2014; He et al., 2016). Moreover, TNF $\alpha$ exerted this effect in part by antagonizing expression of the ER chaperone proteins ERP44 and DSBA-L (He et al., 2016). Accordingly, we asked whether inhibition of adiponectin secretion in medium is exclusively due to inhibition of adiponectin transcription or, in part, due to changes in expression of ER chaperones. However, TNFa failed to inhibit expression of ERP 44 and $D S B A-L$ in bovine adipocytes. These data suggest that reduced adiponectin gene transcription, rather than post-transcriptional mechanisms, accounts for the $\mathrm{TNF} \alpha$-induced suppression of adiponectin secretion in bovine adipocytes. In contrast to $\mathrm{TNF} \alpha$-mediated suppression of adiponectin secretion, GH treatment failed to alter adiponectin mRNA or secretion in medium in bovine adipocytes. This result is inconsistent with an inverse relation between $\mathrm{GH}$ and adiponectin in rodents and humans (Lam et al., 2004; Kanety et al., 2009; Lubbers et al., 2013) but in agreement with the failure of chronic GH treatment to alter plasma adiponectin in transition dairy cows (Krumm et al., 2017).

In summary, we found that $X B P 1 s$ expression in adipose tissue decreased from LP to EL in the transition dairy cow. Using an in vitro system based on adipogenic differentiation of bovine preadipocytes, we showed that $X B P 1 s$ overexpression regulated expression of the ER chaperone proteins GRP78, ERP44, and PDIA6 but not expression or secretion of adiponectin. Finally, we showed that adiponectin secretion by bovine adipocytes required the presence of exogenous lipid and was suppressed by $\mathrm{TNF} \alpha$; none of these effects, however, were associated with regulation of ER chaperone expression. Overall, our data do not support a role for XBP1and its dependent set of ER chaperones in accounting for the variation of plasma adiponectin in transition dairy cows. Other factors that could contribute to the lack of correspondence between changes in plasma adiponectin and its expression in adipose tissue in transition dairy cows include variation in the mRNA regulation and production of adiponectin across adipose tissue depots (e.g., subcutaneous vs. internal depots; Saremi et al., 2014; Singh et al., 2014b), translational regulation of the adiponectin transcript (Banga et al., 2009), and variation in the modifications required for efficient secretion (e.g., hydroxylation or glycosylation; Wang et al., 2002).

\section{ACKNOWLEDGMENTS}

This material is based upon work that is supported by the National Institute of Food and Agriculture, US Department of Agriculture (Washington, DC), under award number 2014-67015-21592 and Hatch/Multistate project under 1000962. We thank Lisa Furman (Cornell University, Ithaca, NY) for her help in performing adipose tissue biopsies used for isolation of bovine preadipocytes and Viju V. Pillai (Cornell University, Ithaca, NY) for his help in constructing the bovine XBP1s adenovirus.

\section{REFERENCES}

Banga, A., R. Unal, P. Tripathi, I. Pokrovskaya, R. J. Owens, P. A. Kern, and G. Ranganathan. 2009. Adiponectin translation is increased by the PPARgamma agonists pioglitazone and omega-3 fatty acids. Am. J. Physiol. Endocrinol. Metab. 296:E480-E489. https://doi.org/10.1152/ajpendo.90892.2008.

Bauman, D. E., and R. G. Vernon. 1993. Effects of exogenous bovine somatotropin on lactation. Annu. Rev. Nutr. 13:437-461. https:// doi.org/10.1146/annurev.nu.13.070193.002253.

Behre, C. J., A. Gummesson, M. Jernås, T. C. Lystig, B. Fagerberg, B. Carlsson, and L. M. S. Carlsson. 2007. Dissociation between adipose tissue expression and serum levels of adiponectin during and after diet-induced weight loss in obese subjects with and without the metabolic syndrome. Metabolism 56:1022-1028. https:// doi.org/10.1016/j.metabol.2007.03.010.

Bell, A. W. 1995. Regulation of organic nutrient metabolism during transition from late pregnancy to early lactation. J. Anim. Sci. 73:2804-2819.

Bell, A. W., and D. E. Bauman. 1997. Adaptations of glucose metabolism during pregnancy and lactation. J. Mammary Gland Biol. Neoplasia 2:265-278.

Block, S. S., W. R. Butler, R. A. Ehrhardt, A. W. Bell, M. E. Van Amburgh, and Y. R. Boisclair. 2001. Decreased concentration of plasma leptin in periparturient dairy cows is caused by negative energy balance. J. Endocrinol. 171:339-348.

Boisclair, Y. R., D. Seto, S. Hsieh, K. R. Hurst, and G. T. Ooi. 1996 Organization and chromosomal localization of the gene encoding the mouse acid labile subunit of the insulin-like growth factor binding complex. Proc. Natl. Acad. Sci. USA 93:10028-10033.

Boisclair, Y. R., S. R. Wesolowski, J. W. Kim, and R. A. Ehrhardt. 2006. Role of growth hormone and leptin in the periparturient dairy cow. Pages 327-346 in Proceedings of the Xth International Symposium on Ruminant Physiology. K. Sejrsen, T. Hveplund, and M. O. Nielsen, ed. Wageningen Academic Publishers, Wageningen, the Netherlands.

Chang, E., J. M. Choi, W. J. Kim, E.-J. Rhee, K. W. Oh, W.-Y. Lee, S. E. Park, S. W. Park, and C.-Y. Park. 2014. Restoration 
of adiponectin expression via the ERK pathway in TNFo-treated 3T3-L1 adipocytes. Mol. Med. Rep. 10:905-910. https://doi.org/ 10.3892/mmr.2014.2278.

Dadson, K., Y. Liu, and G. Sweeney. 2011. Adiponectin action: A combination of endocrine and autocrine/paracrine effects. Front. Endocrinol. (Lausanne) 2:62. https://doi.org/10.3389/fendo.2011 .00062 .

DeClercq, V., B. d'Eon, and R. S. McLeod. 2015. Fatty acids increase adiponectin secretion through both classical and exosome pathways. Biochim. Biophys. Acta 1851:1123-1133. https://doi.org/10 1016/j.bbalip.2015.04.005

Fasshauer, M., J. Klein, S. Neumann, M. Eszlinger, and R. Paschke. 2002. Hormonal regulation of adiponectin gene expression in 3T3L1 adipocytes. Biochem. Biophys. Res. Commun. 290:1084-1089. https://doi.org/10.1006/bbrc.2001.6307.

Giesy, S. L., B. Yoon, W. B. Currie, J. W. Kim, and Y. R. Boisclair. 2012. Adiponectin deficit during the precarious glucose economy of early lactation in dairy cows. Endocrinology 153:5834-5844. https://doi.org/10.1210/en.2012-1765.

Glimcher, L. H. 2010. XBP1: The last two decades. Ann. Rheum. Dis. 69(Suppl 1):i67-i71. https://doi.org/10.1136/ard.2009.119388.

Gregor, M. F., E. S. Misch, L. Yang, S. Hummasti, K. E. Inouye, A.-H. Lee, B. Bierie, and G. S. Hotamisligil. 2013. The role of adipocyte XBP1 in metabolic regulation during lactation. Cell Reports 3:1430-1439. https://doi.org/10.1016/j.celrep.2013.03.042.

He, Y., L. Lu, X. Wei, D. Jin, T. Qian, A. Yu, J. Sun, J. Cui, and Z Yang. 2016. The multimerization and secretion of adiponectin are regulated by TNF-alpha. Endocrine 51:456-468. https://doi.org/ 10.1007/s12020-015-0741-4.

Hotta, K., T. Funahashi, N. L. Bodkin, H. K. Ortmeyer, Y. Arita, B. C. Hansen, and Y. Matsuzawa. 2001. Circulating concentrations of the adipocyte protein adiponectin are decreased in parallel with reduced insulin sensitivity during the progression to type 2 diabetes in rhesus monkeys. Diabetes 50:1126-1133.

Kadowaki, T., and T. Yamauchi. 2005. Adiponectin and adiponectin receptors. Endocr. Rev. 26:439-451. https://doi.org/10.1210/er .2005-0005.

Kadowaki, T., T. Yamauchi, and N. Kubota. 2008. The physiological and pathophysiological role of adiponectin and adiponectin receptors in the peripheral tissues and CNS. FEBS Lett. 582:74-80. https://doi.org/10.1016/j.febslet.2007.11.070.

Kanety, H., R. Hemi, S. Ginsberg, C. Pariente, E. Yissachar, E. Barhod, T. Funahashi, and Z. Laron. 2009. Total and high molecular weight adiponectin are elevated in patients with Laron syndrome despite marked obesity. Eur. J. Endocrinol. 161:837-844. https:// doi.org/10.1530/EJE-09-0419.

Kim, J.-Y., E. van de Wall, M. Laplante, A. Azzara, M. E. Trujillo, S. M. Hofmann, T. Schraw, J. L. Durand, H. Li, G. Li, L. A. Jelicks, M. F. Mehler, D. Y. Hui, Y. Deshaies, G. I. Shulman, G. J. Schwartz, and P. E. Scherer. 2007. Obesity-associated improvements in metabolic profile through expansion of adipose tissue. J. Clin. Invest. 117:2621-2637. https://doi.org/10.1172/JCI31021.

Krumm, C. S., S. L. Giesy, L. S. Caixeta, W. R. Butler, H. Sauerwein, J. W. Kim, and Y. R. Boisclair. 2017. Effect of hormonal and energy-related factors on plasma adiponectin in transition dairy cows. J. Dairy Sci. https://doi.org/10.3168/jds.2017-13274.

Lam, K. S.-L., A. Xu, K. C.-B. Tan, L.-C. Wong, S.-C. Tiu, and S. Tam. 2004. Serum adiponectin is reduced in acromegaly and normalized after correction of growth hormone excess. J. Clin. Endocrinol. Metab. 89:5448-5453. https://doi.org/10.1210/jc.2003 $-032023$.

Lee, A.-H., N. N. Iwakoshi, and L. H. Glimcher. 2003. XBP-1 regulates a subset of endoplasmic reticulum resident chaperone genes in the unfolded protein response. Mol. Cell. Biol. 23:7448-7459.

Lemor, A., A. Hosseini, H. Sauerwein, and M. Mielenz. 2009. Transition period-related changes in the abundance of the mRNAs of adiponectin and its receptors, of visfatin, and of fatty acid binding receptors in adipose tissue of high-yielding dairy cows. Domest. Anim. Endocrinol. 37:37-44. https://doi.org/10.1016/j.domaniend .2009 .01 .004
Lengi, A. J., and B. A. Corl. 2010. Factors influencing the differentiation of bovine preadipocytes in vitro. J. Anim. Sci. 88:1999-2008. https://doi.org/10.2527/jas.2009-2439.

Lim, J.-Y., W. H. Kim, and S. I. Park. 2008. GO6976 prevents TNFalpha-induced suppression of adiponectin expression in 3T3-L1 adipocytes: Putative involvement of protein kinase C. FEBS Lett. 582:3473-3478. https://doi.org/10.1016/j.febslet.2008.09.012.

Liu, M., and F. Liu. 2009. Transcriptional and post-translational regulation of adiponectin. Biochem. J. 425:41-52. https://doi.org/10 .1042/BJ20091045.

Liu, M., R. Xiang, S. A. Wilk, N. Zhang, L. B. Sloane, K. Azarnoush, L. Zhou, H. Chen, G. Xiang, C. A. Walter, S. N. Austad, N. Musi, R. A. DeFronzo, R. Asmis, P. E. Scherer, L. Q. Dong, and F. Liu. 2012. Fat-specific DsbA-L overexpression promotes adiponectin multimerization and protects mice from diet-induced obesity and insulin resistance. Diabetes 61:2776-2786. https://doi.org/10 $.2337 / \mathrm{db} 12-0169$.

Liu, M., L. Zhou, A. Xu, K. S. L. Lam, M. D. Wetzel, R. Xiang, J. Zhang, X. Xin, L. Q. Dong, and F. Liu. 2008. A disulfide-bond A oxidoreductase-like protein (DsbA-L) regulates adiponectin multimerization. Proc. Natl. Acad. Sci. USA 105:18302-18307. https:// doi.org/10.1073/pnas.0806341105.

Lubbers, E. R., E. O. List, A. Jara, L. Sackman-Sala, J. CordobaChacon, M. D. Gahete, R. D. Kineman, R. Boparai, A. Bartke, J. J. Kopchick, and D. E. Berryman. 2013. Adiponectin in mice with altered GH action: Links to insulin sensitivity and longevity? J. Endocrinol. 216:363-374. https://doi.org/10.1530/JOE-12-0505.

Luo, J., Z.-L. Deng, X. Luo, N. Tang, W.-X. Song, J. Chen, K. A. Sharff, H. H. Luu, R. C. Haydon, K. W. Kinzler, B. Vogelstein, and T.-C. He. 2007. A protocol for rapid generation of recombinant adenoviruses using the AdEasy system. Nat. Protoc. 2:12361247. https://doi.org/10.1038/nprot.2007.135.

Maeda, N., I. Shimomura, K. Kishida, H. Nishizawa, M. Matsuda, H. Nagaretani, N. Furuyama, H. Kondo, M. Takahashi, Y. Arita, R. Komuro, N. Ouchi, S. Kihara, Y. Tochino, K. Okutomi, M. Horie, S. Takeda, T. Aoyama, T. Funahashi, and Y. Matsuzawa. 2002. Diet-induced insulin resistance in mice lacking adiponectin/ ACRP30. Nat. Med. 8:731-737. https://doi.org/10.1038/nm724.

Mielenz, M., B. Mielenz, S. P. Singh, C. Kopp, J. Heinz, S. Häussler, and H. Sauerwein. 2013. Development, validation, and pilot application of a semiquantitative Western blot analysis and an ELISA for bovine adiponectin. Domest. Anim. Endocrinol. 44:121-130. https://doi.org/10.1016/j.domaniend.2012.10.004.

Nawrocki, A. R., M. W. Rajala, E. Tomas, U. B. Pajvani, A. K. Saha, M. E. Trumbauer, Z. Pang, A. S. Chen, N. B. Ruderman, H. Chen, L. Rossetti, and P. E. Scherer. 2006. Mice lacking adiponectin show decreased hepatic insulin sensitivity and reduced responsiveness to peroxisome proliferator-activated receptor gamma agonists. J. Biol. Chem. 281:2654-2660. https://doi.org/10.1074/ jbc.M505311200.

Nilsson, L., N. Binart, M. Bohlooly-Y, M. Bramnert, E. Egecioglu, J. Kindblom, P. A. Kelly, J. J. Kopchick, C. J. Ormandy, C. Ling, and H. Billig. 2005. Prolactin and growth hormone regulate adiponectin secretion and receptor expression in adipose tissue. Biochem. Biophys. Res. Commun. 331:1120-1126. https://doi.org/10 .1016/j.bbrc.2005.04.026.

Ortiz-Colón, G., A. C. Grant, M. E. Doumit, and D. D. Buskirk. 2009. Bovine intramuscular, subcutaneous, and perirenal stromalvascular cells express similar glucocorticoid receptor isoforms, but exhibit different adipogenic capacity. J. Anim. Sci. 87:1913-1920. https://doi.org/10.2527/jas.2008-1350.

Pires, J. A. A., A. H. Souza, and R. R. Grummer. 2007. Induction of hyperlipidemia by intravenous infusion of tallow emulsion causes insulin resistance in Holstein cows. J. Dairy Sci. 90:2735-2744. https://doi.org/10.3168/jds.2006-759.

Raffelsieper, M., B. Mielenz, S. Häußler, H. Sauerwein, M. Mielenz, and H. Illges. 2012. A monoclonal antibody against bovine adiponectin. Hybridoma (Larchmt) 31:465-468. https://doi.org/10 $.1089 /$ hyb.2012.0054. 
Rico, J. E., V. V. R. Bandaru, J. M. Dorskind, N. J. Haughey, and J. W. McFadden. 2015. Plasma ceramides are elevated in overweight Holstein dairy cows experiencing greater lipolysis and insulin resistance during the transition from late pregnancy to early lactation. J. Dairy Sci. 98:7757-7770. https://doi.org/10.3168/jds.2015 -9519 .

Rutkowski, J. M., and P. E. Scherer. 2014. Isolation and quantitation of adiponectin higher order complexes. Methods Enzymol. 537:243-259. https://doi.org/10.1016/B978-0-12-411619-1.00013 $-6$.

Sadri, H., R. M. Bruckmaier, H. R. Rahmani, G. R. Ghorbani, I. Morel, and H. A. van Dorland. 2010. Gene expression of tumour necrosis factor and insulin signalling-related factors in subcutaneous adipose tissue during the dry period and in early lactation in dairy cows. J. Anim. Physiol. Anim. Nutr. (Berl.) 94:e194-e202. https://doi.org/10.1111/j.1439-0396.2010.01005.x.

Saremi, B., S. Winand, P. Friedrichs, A. Kinoshita, J. Rehage, S. Dänicke, S. Häussler, G. Breves, M. Mielenz, and H. Sauerwein. 2014. Longitudinal profiling of the tissue-specific expression of genes related with insulin sensitivity in dairy cows during lactation focusing on different fat depots. PLoS One 9:e86211 https://doi.org/10 .1371/journal.pone.0086211.

Sha, H., L. Yang, M. Liu, S. Xia, Y. Liu, F. Liu, S. Kersten, and L. Qi. 2014. Adipocyte spliced form of X-box-binding protein 1 promotes adiponectin multimerization and systemic glucose homeostasis. Diabetes 63:867-879. https://doi.org/10.2337/db13-1067.

Shoulders, M. D., L. M. Ryno, J. C. Genereux, J. J. Moresco, P. G. Tu, C. Wu, J. R. Yates, A. I. Su, J. W. Kelly, and R. L. Wiseman. 2013. Stress-independent activation of XBP1s and/or ATF6 reveals three functionally diverse ER proteostasis environments. Cell Reports 3:1279-1292. https://doi.org/10.1016/j.celrep.2013 .03 .024

Singh, S. P., S. Häussler, J. J. Gross, F. J. Schwarz, R. M. Bruckmaier, and H. Sauerwein. 2014a. Short communication: Circulating and milk adiponectin change differently during energy deficiency at different stages of lactation in dairy cows. J. Dairy Sci. 97:15351542. https://doi.org/10.3168/jds.2013-7598.

Singh, S. P., S. Häussler, J. F. L. Heinz, S. H. Akter, B. Saremi, U. Müller, J. Rehage, S. Dänicke, M. Mielenz, and H. Sauerwein. 2014b. Lactation driven dynamics of adiponectin supply from different fat depots to circulation in cows. Domest. Anim. Endocrinol. 47:35-46. https://doi.org/10.1016/j.domaniend.2013.12.001.
Tchkonia, T., Y. D. Tchoukalova, N. Giorgadze, T. Pirtskhalava, I Karagiannides, R. A. Forse, A. Koo, M. Stevenson, D. Chinnappan, A. Cartwright, M. D. Jensen, and J. L. Kirkland. 2005. Abundance of two human preadipocyte subtypes with distinct capacities for replication, adipogenesis, and apoptosis varies among fat depots. Am. J. Physiol. Endocrinol. Metab. 288:E267-E277. https:// doi.org/10.1152/ajpendo.00265.2004.

Wang, C.-T., A. E. Jetzt, J.-S. Cheng, and W. S. Cohick. 2011. Inhibition of the unfolded protein response by ricin a-chain enhances its cytotoxicity in mammalian cells. Toxins (Basel) 3:453-468. https://doi.org/10.3390/toxins3050453.

Wang, Y., K. S. L. Lam, M. Yau, and A. Xu. 2008. Post-translational modifications of adiponectin: Mechanisms and functional implications. Biochem. J. 409:623-633. https://doi.org/10.1042/ BJ20071492.

Wang, Y., A. Xu, C. Knight, L. Y. Xu, and G. J. S. Cooper. 2002 Hydroxylation and glycosylation of the four conserved lysine residues in the collagenous domain of adiponectin. Potential role in the modulation of its insulin-sensitizing activity. J. Biol. Chem. 277:19521-19529. https://doi.org/10.1074/jbc.M200601200.

Wang, Z. V., and P. E. Scherer. 2008. DsbA-L is a versatile player in adiponectin secretion. Proc. Natl. Acad. Sci. USA 105:1807718078. https://doi.org/10.1073/pnas.0810027105.

Wang, Z. V., and P. E. Scherer. 2016. Adiponectin, the past two decades. J. Mol. Cell Biol. 8:93-100. https://doi.org/10.1093/jmcb/ mjw011.

Wang, Z. V., T. D. Schraw, J.-Y. Kim, T. Khan, M. W. Rajala, A. Follenzi, and P. E. Scherer. 2007. Secretion of the adipocyte-specific secretory protein adiponectin critically depends on thiol-mediated protein retention. Mol. Cell. Biol. 27:3716-3731. https://doi.org/ 10.1128/MCB.00931-06.

Xu, A., K. W. Chan, R. L. C. Hoo, Y. Wang, K. C. B. Tan, J. Zhang, B. Chen, M. C. Lam, C. Tse, G. J. S. Cooper, and K. S. L. Lam. 2005. Testosterone selectively reduces the high molecular weight form of adiponectin by inhibiting its secretion from adipocytes. J. Biol. Chem. 280:18073-18080. https://doi.org/10.1074/jbc .M414231200.

Zhou, Y., A. V. Capuco, and H. Jiang. 2008. Involvement of connective tissue growth factor (CTGF) in insulin-like growth factor-I (IGF1) stimulation of proliferation of a bovine mammary epithelial cel line. Domest. Anim. Endocrinol. 35:180-189. https://doi.org/10 .1016/j.domaniend.2008.05.003. 